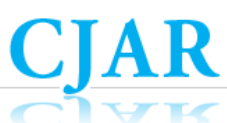

Canadian Journal of Action Research

Volume 20, Issue 2, 2020, 68-84

\title{
UNDERSTANDING EFFECTIVE DEVELOPMENT: USING A COMMUNITY-ACADEMIC PARTNERSHIP TO CREATE A WORKSHOP AND INTERACTIVE TOOLKIT FOR PARENT EDUCATION
}

\author{
Sara Santarossa \\ University of Windsor \\ Sarah J. Woodruff \\ University of Windsor
}

\begin{abstract}
A paucity of research exists on using action research with parents, particularly within the framework of parent education. The current study explores the development phase of a community-academic partnership (CAP) that designed a workshop and interactive toolkit to educate mothers on how to navigate social networking sites. The CAP $(N=10)$ was comprised of researchers, a community organization, and a group of mothers interested in the development of the parent education program. Participants completed an online survey wherein they endorsed and ranked the importance of facilitating and hindering factors present in the formation of the collaborative process, as well as provided formal feedback on the CAP. Although both collaborative processes (interpersonal and operational) were referenced as influential facilitating factors during the CAP's development, operational processes were expressed as facilitators more often. Similar to other action research, it appears that hindering factors are commonly not experienced during the development phase. In addition, it appears a quality action research project was conducted based on the successful fulfillment of partnership and participation, action, reflection, and significance. Overall, this study specifically makes a significant contribution to action research as it pertains to the development of parent education.
\end{abstract}

KEYwoRDS: Action research; Community-Academic Partnership (CAP); Parent education 


\section{INTRODUCTION}

In the offline world, research suggests that the mother/daughter relationship influences every state of the daughter's development (Flaake, 2005), however, parents tend to feel unprepared to raise children in the online, media-rich world we live in today (Yardi \& Bruckman, 2011). Recent research has suggested that within the mother/daughter relationship, girls (11-14 years) feel that their mothers do not understand how to use social networking sites (SNSs) and that if they are on these platforms, they need to act as role models to their daughters (Santarossa \& Woodruff, 2019a). Moreover, findings have suggested that a mother's SNS behaviours are associated with their daughter's (11-14 years) psychosocial well-being (i.e., self-esteem, body satisfaction, internalization of beauty standards, eating disorder symptoms and concerns, and physical activity (Santarossa \& Woodruff, 2019b). Thus, scholars and community practitioners need to facilitate the flow of research knowledge about online parenting practices to those who can help young adolescents regulate negative affect as a means of preventing the development of harmful or excessive behaviours (e.g., eating disorders, poor body image, and low self-esteem). Although children need to learn how to contribute positively to their own digital footprint, parents need to understand that they also play a large role in shaping their children's digital identity. A promising component in the development of an effective parent education program/tool is the use of action research (Loizou, 2013).

Reason and Bradbury (2001) described action research as "a family of practices of living inquiry that aims, in a great variety of ways, to link practice and ideas in the service of human flourishing," where the orientation of change is with others (p. 1). An umbrella term, action research is an 'orientation to inquiry' that seeks answers to questions by working with participants, through constant cycles of action and reflection to produce practical knowledge that can be used by people in their everyday lives, while working together to address problems and create positive change (Bradbury Huang, 2010; Reason \& Bradbury, 2001). Community-academic partnerships (CAPs), falling under the practices of action research, are designed to increase collaboration between researchers and the community. Drahota et al. (2016) has defined CAPs as "partnerships in which researchers and community stakeholders have equitable control in addressing a cause(s) that is primarily relevant to the community of interest and aims to achieve a goal(s) relevant to both community members (representatives or agencies) and researchers" (p. 192). CAPs are not one directional and thus, are addressing the needs for improved collaboration between academics and community practitioners hoping to disseminate and implement promising interventions and community programs (Drahota et al., 2016). CAPs are believed to increase the effectiveness and feasibility of action research (Drahota et al., 2016; Gomez, Drahota, \& Stahmer, 2018).

Although there is a rich body of literature on the process of action research, a paucity exists on using action research with parents, particularly within the framework of parent education (Loizou, 2013). Parent education has been described as a process during which parents are 'educated' to support their children's development and learning, to enhance their parenting identity, and strengthen their parent-child relationship (Croake \& Glover, 
1977). The attempt to educate parents looks differently according to the goals and expectations of every program wherein, specific activities are developed to enhance parents' knowledge, skills, and strategies to support their children and deal with specific issues (Loizou, 2013). The establishment of CAPs in research where academics, parents, and community-based organizations were actively engaged in the design, implementation, and evaluation of parent education programs have fared well (Davison, Jurkowski, Li, Kranz, \& Lawson, 2013; Loizou, 2013). However, the existing literature provides limited guidance on how to develop successful CAPs, it is criticized with being descriptive, and is not focused on specific factors that influence the development phase (i.e., initiation and early period) of the CAP but rather factors that sustain it (Drahota et al., 2016; Gomez et al., 2018). Thus, as much of the current research has not focused on the factors that influence success over the developmental course of CAPs (Drahota et al., 2016), the focus of the current study was to build on the work of Gomez et al. (2018) wherein the development phase was specifically explored.

According to the theory-based Model of Research-Community Partnerships as proposed by Gomez et al. (2018), there are three phases (i.e., Formation, Execution of Activities, and Sustainment) to illustrate the iterative processes of research-community partnership development and conceptualize outcome constructs of these efforts. Across the three phases in the Model of Research-Community Partnerships (Gomez et al., 2018) important processes correspond to each phase: (1) the Formation phase corresponds with the collaboration process and development of the CAP (i.e., Interpersonal and Operational Processes) and subsequent facilitating and hindering factors, (2) the Execution of Activities phase includes proximal (process) outcomes (e.g., knowledge exchange) focusing on the partnership functioning of the CAP, and (3) the Sustainment phase coincides with distal outcomes of the CAP (e.g., improved community care, policy changes). Recently, Gomez et al. (2018) used the aforementioned model to explore the facilitating and hindering factors (as identified in Drahota et al., 2016 systematic review) during a CAP's development phase by categorizing these factors as either Interpersonal or Operational Processes (see Table 1). Interpersonal processes have been defined as "constructs pertaining to the quality of relationships or communication among CAP members" (Gomez et al., 2018, p. 15). Whereas in comparison, operational processes "include constructs pertaining to the logistics and quality of partnership functioning, such as meeting quality, partnership member selection, and finances" (Gomez et al., 2018, p. 15).

Overall the aim of this action research project was to use a CAP to create an evidencebased, sustainable, and usable outreach service for a community organization to use and evaluate in the future. The collaborating community organization specializes in the treatment and prevention of eating disorders through clinical programs and health promotion services, and currently offers media literacy education and presentations on self-esteem, body image, nutrition, physical activity, size acceptance, and body-based harassment. Therefore, the purpose of the present study was to (1) use a CAP to design a workshop and interactive toolkit to educate mothers on how to navigate SNSs appropriately and create a positive digital footprint while creating a transformative 
learning experience for the mothers with the desired impact to then reach their daughter, (2) highlight the development of this workshop and interactive toolkit, and (3) specifically explore the relative influence of facilitating and hindering factors while being guided by the Model of Research-Community Partnership (Gomez et al., 2018) within the CAP during the development phase using an online survey.

\section{METHOD}

The current study uses the Model of Research-Community Partnership (Gomez et al., 2018) to assist in guiding and evaluating the development of the CAP as well as to interpret outcomes of the partnership effort during this development phase. The CAP was comprised of researchers, the community organization, and a group of mothers interested in the development of a parent education program. Specifically, as established by the partners, the goal of the CAP was to develop a workshop and interactive toolkit that would educate mothers by exchanging knowledge about online parenting practices, promoting positive use of SNSs, understanding how SNSs can impact psychosocial well-being (i.e., body image, self-esteem, eating disorders), understanding how to model SNS behaviours appropriately, and to create a positive digital footprint.

\section{DEVELOPING THE WORKSHOP AND INTERACTIVE TOOLKIT Building Relationships}

The authors have been working alongside the community organization for several years on a number of research and community outreach endeavours. This was the first time, however, that the CAP and the Model of Research-Community Partnership (Gomez et al., 2018) was used to develop and evaluate a collaborative effort. The research described in this article was carried out in partial fulfillment of the first author's doctoral degree in Kinesiology. Santarossa collected formative data with mother/daughter dyads through focus groups (Santarossa \& Woodruff, 2019a) and online surveys (Santarossa \& Woodruff, $2019 \mathrm{~b}$ ) to assist in the development of the CAP as well as the workshop and interactive toolkit. The formative data collection allowed the first author to build a relationship with mothers in the community, who then became important stakeholders in the CAP.

\section{Participants}

A total of 10 participants, located in Southwestern Ontario, Canada, were recruited by the Santarossa to help develop the workshop and interactive toolkit. Participants included one academic, one undergraduate student, two members of the community organization's Health Promotion Team (who would be the ones eventually implementing the workshop and interactive toolkit in the community), the community organization's Executive Director, the community organization's Communications and Office Administrator, and four mothers from the community. The academic and the undergraduate student were recruited based on their interest and expertise in the area and their familiarity with the community organization. To recruit the core group of stakeholders from the community organization the first author circulated several emails as well as held information sessions at the community organization to explain the project and outline the goals. To recruit the mothers, emails were circulated to those who had participated in the previous formative 
data collection. Recruitment ran smoothly since many of the partners were familiar with the formative research project. All those who expressed interest in the study ultimately participated $(N=10)$.

\section{Planning meetings}

Participation in the CAP included planning meetings to co-design, review, and provide feedback related to the materials developed by the research team. Santarossa facilitated all planning meetings $(N=4)$. Prior to each meeting, participants were provided an agenda to review and/or a summary of notes from the previous meeting(s). The academic, the undergraduate student, and the community organization stakeholders met with the Santarossa three times for two hours each in a boardroom at the community organization. The academic and the mothers met with the Santarossa for a single planning meeting for two hours that was situated before the last planning meeting with the community organization stakeholders so that ideas could be compared and contrasted. The meetings consisted of clearly defining the aims and objectives of the CAP, providing an understanding to what a CAP is, reviewing previous research in the area of online mother/daughter relationships (i.e., an infographic of the formative data collection created by the first author), numerous interactive activities (e.g., role play, brainstorming, problembased learning), and the use of an evidence-based practice checklist (Sociocultural Approach and the Social Cognitive Theory, Bandura, 2001; Pagoto et al., 2016). Santarossa took time to reflect after each meeting, integrating research and the participant knowledge and experience, and then brought that back to the subsequent meetings.

\section{INTERPRETING OUTCOMES OF PARTNERSHIP EFFORT}

The current study was conducted at the end of the CAP planning meetings and included appropriate institutional research ethics board approval, wherein attending CAP partners had agreed to be recruited prior to the commencement of the planning meetings. To determine which specific factors were perceived to be present within the design phase of the workshop and interactive toolkit as well as the development phase of the CAP, and how influential each selected factor was on the collaborative process, a cross-sectional webbased survey was used to collect both quantitative and qualitative data. Participating CAP partners $(N=10)$ were sent a link via email to the approved consent form and survey using qualtrics.com. Similar to Gomez et al. (2018), a menu of facilitating and hindering factors was listed for participants to choose which were present during the development phase of the CAP. The list of facilitating and hindering factors were developed from the results of a CAP systematic review (Drahota et al., 2016), and additional literature (Brookman-Frazee et al., 2012; Fook, Johannessen \& Psoinos, 2011; Garland, Plemmons, \& Koontz, 2006) was used for the quantitative portion of the CAP survey, followed by three open-ended questions. Complete definitions for the facilitating and hindering factors are outlined in Table 1.

\section{CAP Survey}

The survey consisted of three sections and participants were provided with definitions of CAPs and what the term 'Partner' (i.e., a member of the CAP) referred to. The first section 
asked participants to use a list of facilitating factors that were located on the left hand side of the page and "A. DRAG and DROP the FACILITATING FACTORS into the box on the right that you believe were "present" during the collaborative group process." Participants were then guided as follows: "B. For each factor you selected as "present," RANK (from highest to lowest by moving them up and down within the box) how influential you believe it to be in facilitating the collaborative group process." The second survey section asked participants to use a list of hindering factors that were located on the left hand side of the page and to "A. DRAG and DROP the HINDERING FACTORS into the box on the right that you believe were "present" during the collaborative group process." Participants were guided as follows: "B. For each factor you selected as "present," RANK (from highest to lowest by moving them up and down within the box) how influential you believe it to be in hindering the collaborative group process." Thus, participants ranked all of the facilitating and hindering factors that they selected and did not rank factors that they did not select as present. The third and final section of the survey consisted of open ended questions developed based on questions from the phone interviews conducted in Gomez et al. (2018) and the suggestion from Bailey et al. (2019) that action researchers should consider acquiring formal feedback about their facilitation skills embedded within the action research process. The open-ended questions included:

1. What was the most useful or effective part of the planning session(s) for you?

2. What changes would make the planning session(s) more effective?

3. Additional comments about the facilitator or the planning session(s)?

\section{Data Analysis}

Using the first and second sections of the survey, frequencies, means, standard deviations, and visual inspections were used to rank order the most and least frequently cited factors. Secondly, deductive qualitative analysis was used to analyze the responses from the open ended questions using the facilitating and hindering factors present in Gomez et al. (2018) as a source of codes with further data categorization guided by the interpersonal and operational process factors identified in the Model of Research-Community Partnership (Gomez et al., 2018).

\section{RESULTS}

A total of eight out of ten potential partners participated in the study. Factors were ordered by frequency from most to least frequent (Table 1). The number of facilitating factors selected by participants on the survey ranged from 5 to $12(M=10.5, S D=2.4)$ and no hindering factors were selected by any participant. Open-ended questions were then connected to the quantitative data by the deductive qualitative analysis used. The results are broken down further for both quantitative and qualitative analysis below. 
Table 1

Influential facilitating and hindering factors during a community-academic partnership development phase categorized by collaborate process factors.

\begin{tabular}{|c|c|c|c|c|}
\hline Factor & Definition & Category* & $\begin{array}{l}\text { Selected } \\
(N ; \%)\end{array}$ & $\begin{array}{l}\text { Top } 5 \\
\text { selected } \\
(N ; \%)\end{array}$ \\
\hline $\begin{array}{l}\text { Facilitating } \\
\text { factors }\end{array}$ & $(n=12)$ & & & \\
\hline $\begin{array}{l}\text { Shared vision, } \\
\text { goals, and/or } \\
\text { mission }\end{array}$ & $\begin{array}{l}\text {-Partners share the same identified } \\
\text { vision or values. } \\
\text {-Partners identify the same goals or } \\
\text { mission for CAP. }\end{array}$ & $\begin{array}{l}\text { Inter- } \\
\text { personal }\end{array}$ & $\begin{array}{l}8 ; \\
100.0 \%\end{array}$ & $\begin{array}{l}5 ; \\
62.5 \%\end{array}$ \\
\hline $\begin{array}{l}\text { Effective } \\
\text { and/or } \\
\text { frequent } \\
\text { communication }\end{array}$ & $\begin{array}{l}\text {-Partners engage in ongoing } \\
\text { communication that is open and } \\
\text { respectful. } \\
\text {-Communication that encompasses } \\
\text { personal and professional matters. }\end{array}$ & $\begin{array}{l}\text { Inter- } \\
\text { personal }\end{array}$ & $\begin{array}{l}8 ; \\
100.0 \%\end{array}$ & $\begin{array}{l}5 ; \\
62.5 \%\end{array}$ \\
\hline $\begin{array}{l}\text { Clearly } \\
\text { differentiated } \\
\text { roles/functions } \\
\text { of partners }\end{array}$ & $\begin{array}{l}\text {-Each partner has a specific role in the } \\
\text { group that contributes to its progress. } \\
\text {-CAP has a specific group structure } \\
\text { with different roles for different } \\
\text { partners. }\end{array}$ & Operational & $\begin{array}{l}8 ; \\
100.0 \%\end{array}$ & $\begin{array}{l}4 ; \\
50.0 \%\end{array}$ \\
\hline $\begin{array}{l}\text { Trust between } \\
\text { partners }\end{array}$ & $\begin{array}{l}\text {-Partners have faith in the honesty, } \\
\text { integrity, reliability, and/or } \\
\text { competence of one another. } \\
\text {-Partners are comfortable sharing } \\
\text { because they believe that the sensitive } \\
\text { information that they provide in the } \\
\text { collaboration will remain in the group. }\end{array}$ & $\begin{array}{l}\text { Inter- } \\
\text { personal }\end{array}$ & $\begin{array}{l}7 ; \\
87.5 \%\end{array}$ & $\begin{array}{l}2 ; \\
28.6 \%\end{array}$ \\
\hline $\begin{array}{l}\text { Respect among } \\
\text { partners }\end{array}$ & $\begin{array}{l}\text {-Partners honor and value one } \\
\text { another's opinions. } \\
\text {-Partners are careful to ensure that } \\
\text { each member is able to share his or her } \\
\text { beliefs. }\end{array}$ & $\begin{array}{l}\text { Inter- } \\
\text { personal }\end{array}$ & $\begin{array}{l}7 ; \\
87.5 \%\end{array}$ & $\begin{array}{l}3 ; \\
42.9 \%\end{array}$ \\
\hline $\begin{array}{l}\text { Good } \\
\text { relationship } \\
\text { between } \\
\text { partners }\end{array}$ & $\begin{array}{l}\text {-Partners work well together, group } \\
\text { cohesion, strong reciprocal } \\
\text { relationship, get along well, or like } \\
\text { each other. }\end{array}$ & $\begin{array}{l}\text { Inter- } \\
\text { personal }\end{array}$ & $\begin{array}{l}7 ; \\
87.5 \%\end{array}$ & $\begin{array}{l}3 ; \\
42.9 \%\end{array}$ \\
\hline $\begin{array}{l}\text { Well- } \\
\text { structured } \\
\text { meetings }\end{array}$ & $\begin{array}{l}\text {-Meetings are held with satisfactory or } \\
\text { effective frequency. } \\
\text {-The logistics of the meetings facilitate } \\
\text { productivity, satisfaction, effectiveness, } \\
\text { partnership, opportunities to interact, } \\
\text { etc. (eg., food available, formality/lack }\end{array}$ & Operational & $\begin{array}{l}7 ; \\
87.5 \%\end{array}$ & $\begin{array}{l}5 ; \\
71.4 \%\end{array}$ \\
\hline
\end{tabular}


Good quality of leadership (i.e., the facilitator of the partnership/pl anning sessions) Good initial selection of partners

Positive community impact Mutual benefit for all partners

Effective conflict resolution of formality at meetings).

-The style of the meeting is satisfactory

(e.g., face-to-face, telephone, webbased).

-A person with strong and experienced leadership skills.

-A leader who is open, listens, and takes suggestions into consideration.

-A leader who cares about members of the group.

-Selecting the "right" people to be a part of the collaborative group.

-The personality characteristics of partners contribute to the success of the CAP.

-Partners perceive the group as having/will have a positive impact on the community.

-All partners benefit from the group's progress.

-Benefit may be different, but all receive some benefit.

-Conflicts are discussed and resolved openly by partners.

-The team develops as it deals with problems, tensions, and frustrations.

$\begin{array}{lll}\text { Operational } & 7 ; & 4 ; \\ & 87.5 \% & 57.1 \%\end{array}$

$\begin{array}{lll}\text { Operational } & 6 ; & 3 ; \\ & 75.0 \% & 50.0 \%\end{array}$

$\begin{array}{lll}\text { Operational } & 6 ; & 3 ; \\ & 75.0 \% & 50.0 \%\end{array}$

Operational 6; 3; $75.0 \% \quad 50.0 \%$

Inter- $\quad 5 ; \quad 0$ personal $\quad 62.5 \% \quad 0.0 \%$

\begin{tabular}{|c|c|c|c|c|}
\hline $\begin{array}{l}\text { Hindering } \\
\text { factors }\end{array}$ & $(n=13)$ & & & \\
\hline $\begin{array}{l}\text { Excessive time } \\
\text { commitment }\end{array}$ & $\begin{array}{l}\text {-Partners leave the group, want to } \\
\text { leave the group, or the CAP does not } \\
\text { function well because the time the } \\
\text { partners have to spend collaborating is } \\
\text { too large. }\end{array}$ & Operational & $\begin{array}{l}0 ; \\
0.0 \%\end{array}$ & $\begin{array}{l}0 ; \\
0.0 \%\end{array}$ \\
\hline $\begin{array}{l}\text { Excessive } \\
\text { funding } \\
\text { pressures or } \\
\text { control } \\
\text { struggles }\end{array}$ & $\begin{array}{l}\text {-Partners struggle over control of } \\
\text { funding. } \\
\text {-CAP experiences external pressures } \\
\text { from funding sources related to } \\
\text { decisions, CAP outcomes, or its } \\
\text { progress. }\end{array}$ & Operational & $\begin{array}{l}0 ; \\
0.0 \%\end{array}$ & $\begin{array}{l}0 ; \\
0.0 \%\end{array}$ \\
\hline $\begin{array}{l}\text { Unclear roles } \\
\text { and/or } \\
\text { functions of } \\
\text { partners }\end{array}$ & $\begin{array}{l}\text { - Many or all of the partners do not } \\
\text { know what their role in the group is } \\
\text { supposed to be. } \\
\text {-Partners are not assigned any roles }\end{array}$ & Operational & $\begin{array}{l}0 ; \\
0.0 \%\end{array}$ & $\begin{array}{l}0 ; \\
0.0 \%\end{array}$ \\
\hline
\end{tabular}


and therefore do not know how they

can best contribute to the CAP.

Poor

communication

among

partners

Inconsistent

partner

participation or

membership

High burden of

activities/tasks

Lack of shared

vision, goals, and/or mission

Differing

expectations of

partners

Mistrust among

partners

communication.

-Partners experience difficulty

maintaining communication.

-There is inconsistent or fluctuating partner attendance at meetings.

-CAP membership is inconsistent.

There is attrition or turnover in individuals.

-Some, many, or all members are

dissatisfied with the amount of work

CAP. expensive, not meaningful, or otherwise upsetting. goals, values or mission of the CAP.

-Partners have different agendas/vision for the CAP.

-Struggles emerge because not all

members expect the same structure,

procedures, and/or outcomes.

- Partners do not have faith in one
Lack of

common

language or

shared terms

among

partners

Bad

relationship
-CAP has limited or unclear methods of partnering agencies/organizations or

they have to do in order to sustain the

- Partners are dissatisfied because the

tasks they have to complete are boring,

-There are unclear or undefined vision, another's honesty, integrity, reliability, and/or competence of one another.

-Partners are uncomfortable sharing

because they believe that the sensitive information that they provide in the CAP will not remain in the group.

-Partners lack common terms or definitions related to the topic of interest or work of the CAP.

- Partners lack a shared understanding of the terms used.

-Partners do not value each other's opinions.

- Partners make no effort to ensure that each member is able to share his or her
Operational

0 ;

$0.0 \% \quad 0.0 \%$

Inter-

personal

0

$0.0 \%$

0

$0.0 \%$

$\begin{array}{lll}\text { Operational } & 0 ; & 0 ; \\ & 0.0 \% & 0.0 \%\end{array}$

$0 ; \quad 0$

personal

$0.0 \%$

$0.0 \%$

Operational

$0 ; \quad 0$

$0.0 \% \quad 0.0 \%$

$\begin{array}{lll}\text { Inter- } & 0 ; & 0\end{array}$

personal $\quad 0.0 \% \quad 0.0 \%$

Operational $\quad 0 ; 0.0 \% \quad 0 ; 0.0 \%$

Inter-

$0 ; 0.0 \%$

$0 ; 0.0 \%$ 
beliefs.

$\begin{array}{lllll}\begin{array}{l}\text { Lack of } \\ \text { community } \\ \text { impact }\end{array} & \begin{array}{l}\bullet \text { Partners have perceptions that the } \\ \text { group will not have/did not have a } \\ \text { positive or meaningful impact on the } \\ \text { community. }\end{array} & \text { Operational } & 0 ; 0.0 \% & 0 ; 0.0 \% \\ \begin{array}{l}\text { Lack of mutual } \\ \text { benefit }\end{array} & \begin{array}{l}\bullet \text { Not all members benefit equally from } \\ \text { the group's progress }\end{array} & \text { Operational } & 0 ; 0.0 \% & 0 ; 0.0 \%\end{array}$

Note. Based on Gomez et al., (2018) lack of mutual benefit and lack of community impact do not appear as hindering factors in the paper by Drahota et al. (2016), but were derived from additional literature (cf. Brookman-Frazee et al., 2012; Fook et al., 2011; Garland et al., 2006) and included in the current study.

*Category is based on the Collaborative Process Factors found in the formation phase of the Model of Research-Community Partnership (Gomez et al., 2018; adapted from BrookmanFrazee et al., 2012

\section{QUANTITATIVE (RANK ORDER QUESTIONS)}

At least one participant endorsed each facilitating factor presented in the survey. Of the facilitating factors, three were endorsed by all participants and had a high ranking in the most influential factors facilitating. However, "Well-structured meeting" was ranked as the most influential facilitating factor, yet, it was not endorsed by all participants. Of the top three most influential facilitating factors (i.e., "Shared vision, goals, and/or mission", "Effective and/or frequent communication", and "Well-structured meetings") two were interpersonal process factors and one was an operational process factor. Lastly, no hindering factors were chosen by any participants.

\section{QUALITATIVE (OPEN ENDED QUESTIONS)}

In subsequent paragraphs, each of the three open-ended questions are discussed and the frequency counts are provided to illustrate the number of participants who responded to a particular factor.

What was the most useful or effective part of the planning session(s) for you? Responses were received from all eight participants. This data was categorized into facilitating factors, where six of the 12 facilitating factors were present in the data in which the majority were operational process factors. The most common factor, mentioned by six participants, was "Well-structured meetings", an operational process factor. With a sample quote being, "The structure of the meetings was very effective to not only me, but the success of the group as a whole". "Good quality of leadership (i.e., the facilitator of the partnership/planning sessions)", also an operational process factor, was the next most common factor within the dataset with four participants making reference to the facilitation leader. For example, "Our leader was extremely organized. We could have talked forever but she kept us focused and on task". Two participants indicated the "Respect among partners", an interpersonal process factors, in their response. For example, "I loved that each member was able to 
contribute their strengths and add to the conversation from their own personal lens". Similarly, two participants identified "Good relationship between partners", also an interpersonal process factor, in their response. A sample quote includes, "Collaboration with all of the members was extremely positive". "Positive community impact" was a facilitating factor, an operational process factor, evident in two participants' responses. For example, "It helped to see that there was a need for the research (toolkit) and realize how many people can benefit from it". Finally, one participant identified "Clearly differentiated roles/functions of partners", an operational process factor, suggesting, "Our leader was always well prepared and communicated objectives and desired outcomes with the group".

What changes would make the planning session(s) more effective? All eight participants left a response to this question. This data was categorized into hindering factors. Although five of the participants mentioned that they would change nothing about the planning sessions, two of the 13 hindering factors were present in the data, in which one was an operational and the other an interpersonal process factor. Two participants identified "Unclear roles and/or functions of partners", an operational process factor, as a possible area for planning session effectiveness improvement. For example, "Perhaps adding 1-2 more sessions would be helpful as a 'wrap up meeting' to finalize details". Lastly, one participants' suggestion identified "Lack of shared vision, goals, and/or mission", an interpersonal process factor, as a potential area to address for effectiveness of planning sessions, stating: "The second brainstorming meeting was super effective, but I think some members had a different vision and therefore it was hard for the leader of the group to move towards their vision".

Additional comments about the facilitator or the planning session(s)? Six out of eight participants left a response to this question. This data was categorized into facilitating and/or hindering factors, four of the 12 facilitating factors were present, no hindering factors were present and the majority were operational process factors. Two participants indicated "Good quality of leadership (i.e., the facilitator of the partnership/planning sessions)", an operational process factor, in their response. For example, "Our leader always was very prepared and communicated all details of the project clearly". "Wellstructured meetings" another operational process factor, was mentioned by two participants. With a sample quote being that the meetings were "Excellent and organized". The interpersonal process factor, "Good relationship between partners" was identified in two responses, for example "I think the partners as a whole worked very well together". Finally, one participant alluded to "Positive community impact", an operational processes factor in their response, with the statement: "Was great and looking forward to the outcome!"

\section{DISCUSSION}

This study highlights the use and importance of CAPs in creating a workshop and interactive toolkit designed to educate mothers on how to navigate SNSs appropriately and create a positive digital footprint while creating a transformative learning experience for the mothers with the desired impact to then reach their daughter. The purpose of the larger CAP project is to test and implement this workshop and interactive toolkit in the 
community, however, the current study focuses on specifically exploring the developmental phase of the CAP and the subsequent influential facilitating and hindering factors from the perspective of the collaborative partners. Using an online survey and collecting both quantitative and qualitative data, the developmental phase of the CAP can be discussed not only by influential facilitating and hindering factors but the quality of the action research project can be reviewed. Similar to Bailey et al. (2019), using the quality criteria of partnership and participation, action, reflection, and significance, outlined by Bradbury Huang (2010) and the Journal's criteria for quality (http://journals.sagepub.com/pb-assets/cmscontent/ARJ/ARJ_Quality_ Criteria.pdf), the results of this study can be reviewed in terms of the quality of this CAP's developmental phase.

Understanding the quality of relationships formed with stakeholders and their involvement in inquiry is referred to as partnership and participation (Bradbury Huang, 2010), and in the current study can specifically be described by the results of the survey data. In comparison to previous literature (Gomez et al., 2018), operational processes (vs. interpersonal processes) were referenced as influential facilitating factors more often during the CAP's development, and included having well-structured meetings, strong leadership, a perception of a positive community impact, and clarity of specific roles within the group that contributes to its progress. However, similar to Gomez et al. (2018) there is a need to differentiate the meaning of good quality of leadership, and the role it plays in the CAP development. Future research should aim to better understand leadership as an influential facilitating factor with members of a CAP by distinguishing leadership as an operational process (e.g., organized leadership, closely related to well-structured meetings) and/or an interpersonal process (e.g., personal characteristics of the leader such as charisma). Partnership and participation (Bradbury Huang, 2010) can further be understood through the many interpersonal processes that were found to be influential during the CAP's development, which included having shared group vision, an atmosphere of with open communication, and good relationships between the partners that were respectful. Previous literature (Baliey et al., 2019; Brookman-Frazee et al., 2012; Gomez et al., 2018; Perrault, McClelland, Austin, \& Sieppert, 2011; Sibbald, Tetroe, \& Graham, 2014) has highlighted similar interpersonal factors as important elements of a CAP's success. Notably, as cited in previous literature (Baliey et al., 2019; Gomez et al., 2018) having a shared group vision appears to be of higher importance than other interpersonal processes that are facilitating the development of the CAP, and should be emphasized in future action research projects.

In addition to monitoring the operational and interpersonal processes that have been highlighted as important for the successful development of a CAP, understanding the hindrances and how to mitigate them is also necessary. Research has suggested that to best inform success in future collaborations, lessons learned from unsuccessful experiences should be highlighted in the literature (Perrault et al., 2011). Within the current study, no hindering factors were endorsed by participants in the quantitative sections of the survey. Conversely, the qualitative data revealed that perhaps some members of the CAP felt that 
there were unclear roles and a lack of shared vision. However, future research may better explain this finding through the use of in-depth interviews that would allow the opportunity for probing questions and a more in-depth textual analysis. In addition, these findings may indicate hindering factors are commonly not experienced during the development phase of CAPs, compared to the implementation and/or CAP sustainment and perhaps longitudinal designs are needed (Gomez et al., 2018).

This study being actionable refers to the extent to which it provides new ideas that guide action in response to need (Bradbury Huang, 2010). Based on interaction with the community organization and mothers, as well as various community members (e.g., teachers, principals, social workers), a need was expressed to better understand the online dynamics of the mother/daughter relationship and subsequently create parental education tools that could aid in navigating this relationship. To address the aforementioned need, a CAP with stakeholders (i.e., the community and mothers) who had worked closely with the first author during the formative studies (Santarossa \& Woodruff, 2019a; 2019b) were sought out. The development of this workshop and interactive toolkit is specifically filling a need for the community organization, as they will become actionable as a sustainable component for future implementation and evaluation. However, within the current study, the finding that the interpersonal process of having a shared group vision was one of the most influential facilitating factors during the CAP's development indicates that a mutual need existed.

As a way for Santarossa, as CAP facilitator, to understand and acknowledge her role as an instrument of change among change agents and stakeholders (Bradbury Huang, 2010), reflexivity was used throughout the project. As outlined in the methodology, the first author would reflect after each planning meeting, and spend time integrating the research literature and the participant knowledge and experiences. The first author would then craft summaries and agendas rooted in this reflexive activity and deliver it back to the CAP members at the subsequent meeting, with the hopes of emphasizing the wants and needs of the CAP and the potential for community impact. The reflexivity of the first author appears to be acknowledged by the CAP in that the results suggest facilitating factors such as shared vision, well-structured meetings, leadership, and understanding the potential for positive community impact were seen as influential. These factors comprised of both interpersonal and operational process may indicate the impact of the facilitator's impact and that change efforts are unfolding. Notably, participants endorsing understanding the potential for positive community impact perhaps suggests that the facilitator is significantly impacting the thought process of participants from meeting to meeting. In addition, investigating the findings from the current study allows for reflexivity moving forward into the next stages of the overall project, and will aid in continuing to foster a positive and productive CAP.

Finally, significance, defined as having meaning and relevance beyond an immediate context (Bradbury Huang, 2010), is demonstrated in the current study. The community organization has been provided with an evidence-based, sustainable, and usable outreach service. Within the community, the workshop and interactive toolkit will promote parent 
education for raising children, specifically in terms of the mother/daughter relationship, in the online, media-rich world we live in today. Beyond this immediate study, significance is demonstrated both in the delivery of the workshop throughout the community and in the vast reach that the interactive toolkit can potentially have. Wherein, the final design of the interactive toolkit contains a mobile application housed through the community organization's website, a podcast series, and various innovative worksheets that complement the workshop. All those who participated in the CAP, including the facilitator, will be able to take the lessons learned throughout this development phase and apply them to life beyond the action research project.

\section{LIMITATIONS}

A limitation of the current study is that generalization of findings may be limited in that only a single CAP was explored, thus only representing the perspectives of one stakeholder team. Moreover, this CAP was limited, as only one parental figure (i.e., mothers) was recruited to participate in this collaboration. Thus, the lack of paternal perspective may limit the workshop and interactive toolkit's use to only the maternal parent. In addition, similar to Gomez et al. (2018) a limitation that exists in the current study is that the design is researcher-driven. The list of facilitating and hindering factors, along with the collaborative process classifications were created based on previous literature, opposed to asking the CAP members to provide input. Increasing the involvement of the CAP in the research design and subsequent processes will add value in future action research. Finally, although the open-ended questions provided some additional information, future action research should conduct in depth interviews with CAP members to gain more robust knowledge on the development phase and use probing questions to uncover what aids in facilitating or hindering the collaboration process. In addition, written responses tend to produce short answers and may not contain the rich information oral interviews can generate (Fairweather, Rinne, \& Steel, 2012). Thus, future researchers may consider using a face-to-face interview process as individuals are more likely to elaborate in person, therefore gaining more detailed information on how the participants interpreted the whole action research process. Despite these limitations, the current study provides information to researchers who are looking to conduct quality action research, specifically when it comes to understanding the development phase of CAPs, the collaboration process, and subsequent facilitating and hindering factors.

\section{CONCLUSIONS}

This paper describes the development phase of a CAP to design a workshop and interactive toolkit to educate mothers on how to navigate SNSs appropriately and create a positive digital footprint while creating a transformative learning experience for the mothers with the desired impact to then reach their daughter. Wherein the relative influence of facilitating and hindering factors while being guided by the Model of Research-Community Partnership (Gomez et al., 2018) within the CAP were explored using an online survey. Although both collaborative processes (interpersonal and operational) were referenced as influential facilitating factors during the CAP's development, operational processes were expressed as facilitators more often. Similar to other action research it appears that 
hindering factors are commonly not experienced during the development phase of CAPs. Overall, this study specifically makes a significant contribution to action research as it pertains to the development of parent education. Understanding the facilitating and hindering factors that influence the collaborative process during the development phase of CAPs may in turn lead to successful sustainment over time, maximizing the possible benefits of the CAP and the attempt to educate parents on a desired issue.

\section{REFERENCES}

Bailey, K. A., Gammage, K. L., \& van Ingen, C. (2019). Designing and implementing a positive body image program: Unchartered territory with a diverse team of participants. Action Research, 17(2), 146-161. DOI: 10.1177/1476750318821169

Bandura, A. (2001). Social cognitive theory: An agentic perspective. Annual Review of Psychology, 52(1), 1-26. https://doi.org/10.1146/annurev.psych.52.1.1

Bradbury Huang, H. (2010). What is good action research? Why the resurgent interest? Action Research, 8, 93-109. DOI:10.1177/1476750310362435

Brookman-Frazee, L., Stahmer, A. C., Lewis, K., Feder, J. D., \& Reed, S. (2012). Building a research-community collaborative to improve community care for infants and toddlers at-risk for autism spectrum disorders. Journal of Community Psychology, 40, 715-734. https://doi.org/10.1002/jcop.21501

Croake, J. W., \& Glover, K. E. (1977). A history and evaluation of parent education. Family Coordinator, 151-158. DOI: 10.2307/583363

Davison, K. K., Jurkowski, J. M., Li, K., Kranz, S., \& Lawson, H. A. (2013). A childhood obesity intervention developed by families for families: Results from a pilot study. International Journal of Behavioral Nutrition and Physical Activity,10(1), 3. http://www.ijbnpa.org/content/10/1/3

Drahota, A., Meza, R., Naaf, M., Spurgeon, E., Dufek, S., Estabillo, J., . . Aarons, G. A. (2016). Community-academic partnerships: A systematic review of the state of the literature and recommendations for future research. Milbank Quarterly, 94(1), 163214. DOI: $10.1111 / 1468-0009.12184$

Fairweather, J., Rinne, T., \& Steel, G. (2012). Computer-assisted, self-interviewing (CASI) compared to face-to-face interviewing (FTFI) with open-ended, non-sensitive questions. International Journal of Qualitative Methods,11(3), 280-291. https://doi.org/10.1177/160940691201100307 
Flaake, K. (2005). Girls, adolescence and the impact of bodily changes: Family dynamics and social definitions of the female body. European Journal of Women's Studies, 12(2), 201-212. https://doi.org/10.1177/1350506805051241

Fook, J., Johannessen, A., \& Psoinos, M. (2011). Partnership in practice research: A Norwegian experience. Social Work \& Society, 9(1), 29-44. http://hdl.handle.net/11250/98959

Garland, A. F., Plemmons, D., \& Koontz, L. (2006). Research-practice partnership in mental health: Lessons from participants. Administration and Policy in Mental Health and Mental Health Services Research, 33(5), 517-528. https://doi.org/10.1007/s10488006-0062-2

Gomez, E., Drahota, A., \& Stahmer, A. C. (2018). Choosing strategies that work from the start: A mixed methods study to understand effective development of communityacademic partnerships. Action Research, 1(24). DOI: 10.1177/1476750318775796

Loizou, E. (2013). Empowering parents through an action research parenting program. Action Research, 11(1), 73-91. https://doi.org/10.1177/1476750313476311

Pagoto, S., Waring, M. E., May, C. N., Ding, E. Y., Kunz, W. H., Hayes, R., \& Oleski, J. L. (2016). Adapting behavioral interventions for social media delivery. Journal of Medical Internet Research, 18(1), e24. D0I: 10.2196/jmir.5086

Perrault, E., McClelland, R., Austin, C., \& Sieppert, J. (2011). Working together in collaborations: Successful process factors for community collaboration. Administration in Social Work, 35(3), 282-298. https://doi.org/10.1080/03643107.2011.575343

Reason, P., \& Bradbury, H. (Eds.). (2001). Handbook of action research: Participative inquiry and practice. Thousand Oaks: CA. SAGE.

Santarossa, S., \& Woodruff, S.J. (2019a). Using focus groups to understand the dynamics of mothers and daughters on social networking sites. Manuscript submitted for publication.

Santarossa, S., \& Woodruff, S.J. (2019b). Maternal modeling online: Assessing the dynamics of mother/daughter dyads on social networking sites using the actor-partner interdependence model. Manuscript submitted for publication.

Sibbald, S. L., Tetroe, J., \& Graham, I. D. (2014). Research funder required research partnerships: A qualitative inquiry. Implementation Science, 9(1), 176. http://www.implementationscience.com/content/9/1/176 
Yardi, S., \& Bruckman, A. (2011, May). Social and technical challenges in parenting teens' social media use. In Proceedings of the SIGCHI Conference on Human Factors in Computing Systems (pp. 3237-3246). ACM.

\section{BIOGRAPHICAL NOTE:}

Sara Santarossa is a PhD candidate in the Department of Kinesiology at the University of Windsor, working under Dr. Sarah Woodruff. Sara's research examines the relationship between social media and gender roles, body image, self-esteem, eating behaviours, and eating disorders.

Sarah J. Woodruff is an Associate Professor in the Department of Kinesiology at the University of Windsor. Dr. Woodruff is a multidisciplinary researcher who strives to advance the knowledge surrounding various health behaviours.

\section{FUNDING NOTE:}

The authors are grateful to the Social Sciences and Humanities Research Council for funding that supported this work through the Joseph-Armand Bombardier CGS Doctoral Scholarship. 